\title{
Corrigendum
}

\section{Corrigendum to "Study on Dynamic Response of Downhole Tools under Perforation Impact Load"}

\author{
Liu Jun, ${ }^{1}$ Li Shide, ${ }^{1}$ Liu Qingyou, ${ }^{1,2}$ Liu Xian, ${ }^{1}$ Guo Xiaoqiang, ${ }^{1}$ and He Yufa ${ }^{3}$ \\ ${ }^{1}$ School of Mechatronic Engineering, Southwest Petroleum University, Chengdu, Sichuan 610500, China \\ ${ }^{2}$ Xihua University, Chengdu, Sichuan 610039, China \\ ${ }^{3}$ CNOOC Research Institute, Beijing 100028, China \\ Correspondence should be addressed to Liu Qingyou; liuqy66@aliyun.com
}

Received 29 October 2017; Accepted 5 November 2017; Published 3 December 2017

Copyright (C) 2017 Liu Jun et al. This is an open access article distributed under the Creative Commons Attribution License, which permits unrestricted use, distribution, and reproduction in any medium, provided the original work is properly cited.

In the article titled "Study on Dynamic Response of Downhole Tools under Perforation Impact Load” [1], Acknowledgments should be added as follows:

This paper has been supported in part by the National Basic Research Program of China (the 973 Program), 2015CB251205, and an independent innovation project of the CNOOC Research Institute "Study on Safety of Well Bore and String in Deepwater High Temperature and High Pressure Well" and PetroChina Innovation Foundation no. 2015D-5006-0309.

\section{References}

[1] L. Jun, L. Shide, L. Qingyou, L. Xian, G. Xiaoqiang, and H. Yufa, "Study on dynamic response of downhole tools under perforation impact load," Shock and Vibration, vol. 2017, Article ID 4894032, 10 pages, 2017. 


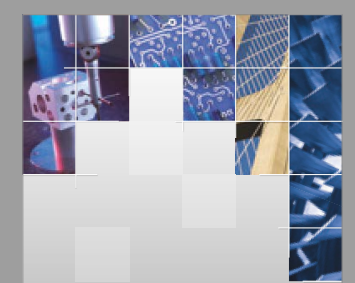

\section{Enfincering}
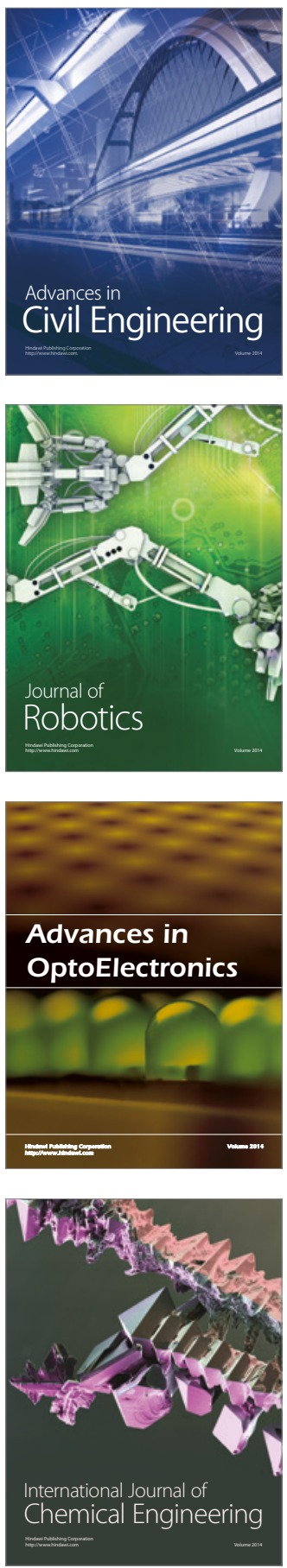

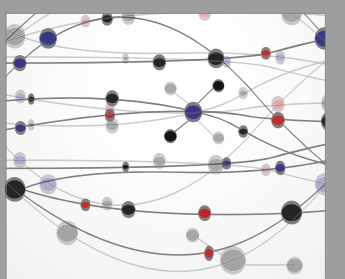

The Scientific World Journal

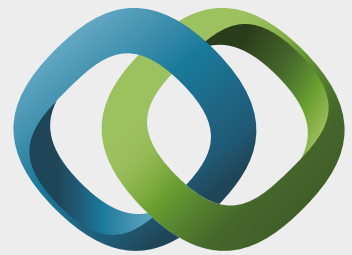

\section{Hindawi}

Submit your manuscripts at

https://www.hindawi.com
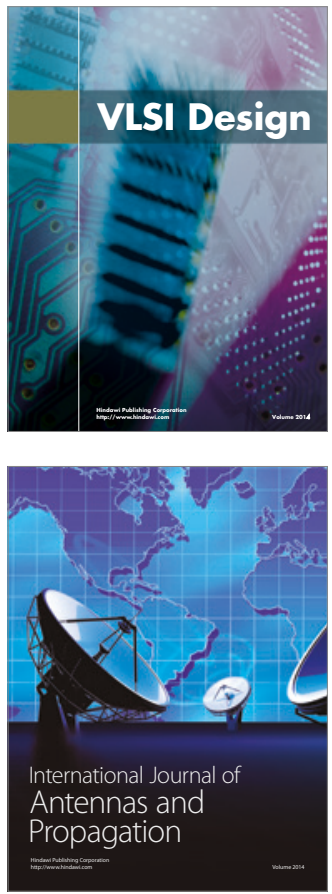

\section{Rotating}

Machinery
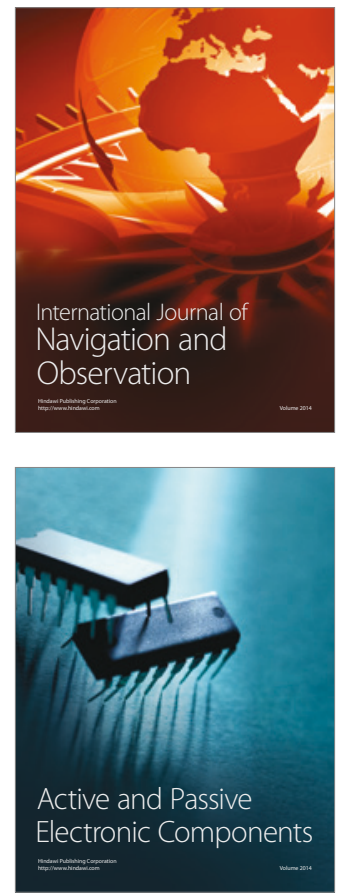
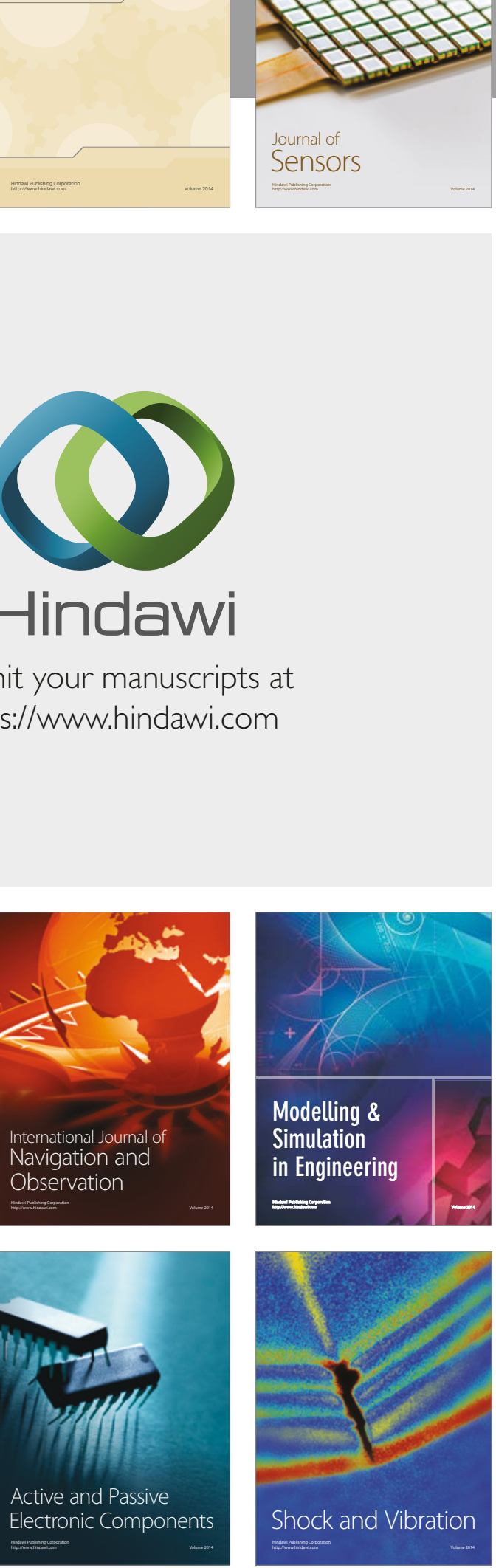
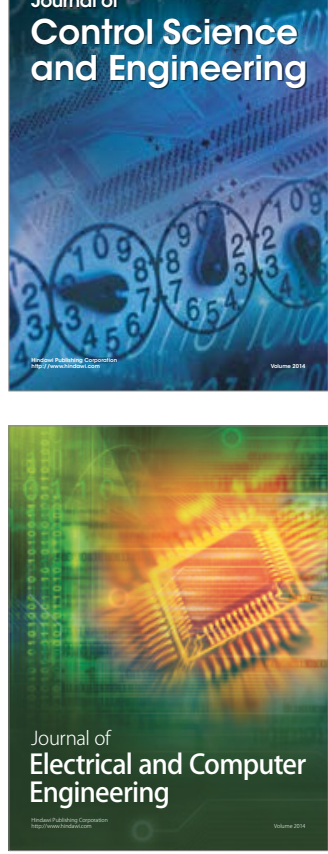

Distributed

Journal of

Control Science

and Engineering
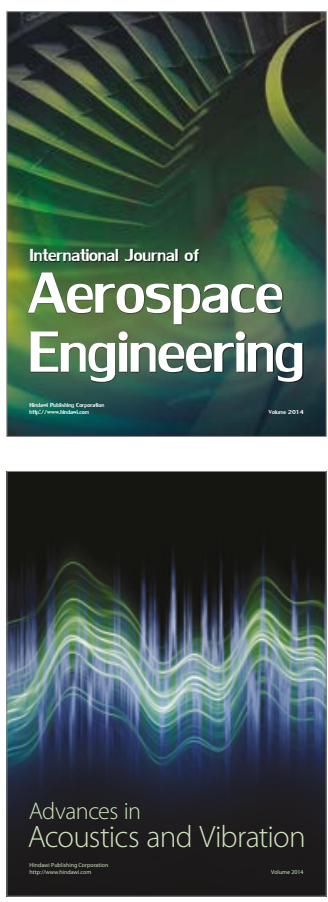

Sensor Networks 